\title{
Chapter 7 \\ Stress Modulation in Pinus spp. Somatic Embryogenesis as Model for Climate Change Mitigation: Stress Is Not Always a Problem
}

\author{
Ander Castander-Olarieta, Catia Pereira, Itziar A. Montalbán, \\ Jorge Canhoto, and Paloma Moncaleán
}

\begin{abstract}
Climate change is leading to higher temperatures and lower precipitation; this fact can have a negative impact on plant performance and survival. Latest findings have revealed that the conditions in which zygotic embryogenesis takes place have an impact on the adaptive capacity of the resulting plants. Somatic embryogenesis provides us a potent biotechnological tool to manipulate the physical and chemical conditions (water availability) along the process and to study their effect in the final success of the process in terms of quantity and quality of somatic plants produced. The development of somatic cells to somatic plantlets comprises three stages: induction of embryonal masses, maturation of embryogenic tissues, and conversion into somatic plants. Our experience in somatic embryogenesis in Pinus spp. enables us to explore the possibility to modulate the quality in terms of abiotic stress tolerance of somatic plants modifying environmental conditions during the initial stages of the process. Our results have shown that the modification of environmental conditions affected not only the success of the process in some species of pines but also the water use efficiency of the somatic plants after several months in ex vitro conditions. In the chapter, we will show the different responses obtained in all the stages of the somatic embryogenesis process as well as the
\end{abstract}

A. Castander-Olarieta $\cdot$ I. A. Montalbán $\cdot$ P. Moncaleán $(\bowtie)$ NEIKER-Tecnalia, Centro de Arkaute, Vitoria-Gasteiz, Spain e-mail: pmoncalean@neiker.eus

C. Pereira

NEIKER-Tecnalia, Centro de Arkaute, Vitoria-Gasteiz, Spain

Centre for Functional Ecology, Department of Life Sciences, University of Coimbra, Coimbra, Portugal

J. Canhoto

Centre for Functional Ecology, Department of Life Sciences, University of Coimbra, Coimbra, Portugal 
response obtained after drought periods in plants growing in the greenhouse under ex vitro conditions.

Keywords Stress modulation · Somatic embryogenesis · Climate change · Mitigation · Pinus spp

\section{Introduction}

As a result of being sessile organisms that are continuously exposed to a huge amount of external stimuli and changing environments, plants have evolved and managed to acquire different mechanisms to rapidly detect and respond to a great variety of stress factors, both biotic and abiotic (Xia et al. 2015). Among abiotic stresses, drought and high temperatures are among the most common environmental constraints for plants. In fact, due to climate change, extreme heat waves and long drought periods are becoming more and more frequent (Duliè et al. 2013), which cause a serious threat not only for natural ecosystems but also for all type of plantations and cultivars (Allen et al. 2010). These conditions are already challenging the survival and productivity of forests (Manzanera et al. 2017). Conifers, by far the largest and most diverse gymnosperm group that grow in a wide range of climate zones, are of great importance both ecologically and economically since they make up most of the biomass in many biogeographic zones of the Northern Hemisphere and provide wood and non-wood products (von Arnold et al. 2018). Nonetheless, the current situation driven by climate change foretells big difficulties to satisfy the future demand of forest products and services (Fenning et al. 2008).

At the molecular level, heat and drought are known to affect a great number of physiological traits. They trigger inhibition of photosynthesis, senescence, water, and osmotic imbalances and production of reactive oxygen species and modify the permeability and fluidity of cell membranes, among others (Larkindale and Knight 2002; Sangwan et al. 2002; Vacca et al. 2004; Feller and Vaseva 2014). However, the great adaptability and phenotypic plasticity of plants offer the opportunity to combine traditional breeding techniques with modern biotechnological tools to obtain plants pre-adapted to different environmental conditions (Conrath et al. 2015). This pre-adaptation strategy is mainly ruled by epigenetic variations, which endow plants with some kind of "memory" that results in modified gene expression patterns (Davies et al. 2011). In this context, somatic embryogenesis (SE) could be a useful tool to modulate future plant tolerance and therefore their behavior in ex vitro conditions. SE is a biotechnological tool in which embryos arise from somatic cells and commonly includes a set of stages such as induction, multiplication (proliferation), maturation, and conversion into plantlets (Heringer et al. 2018). Variation of the culture conditions during initial steps of the SE process is known to have 
long-lasting effects in plants, even altering some developmental traits years later (Kvaalen and Johnsen 2008). Consequently, SE apart from being one of the most effective techniques to obtain large amounts of cloned material in conifers opens the door to a promising research field that could help to unravel the molecular mechanisms by which plants face stress.

To this purpose, in the last few years our research team has been applying different culture and environmental conditions during the different steps of SE, in order to assess if those changes in conditions can determine the success of the SE process itself in terms of plant production and plant quality, but also the behavior of somatic embryo-derived plants ex vitro. In parallel, numerous studies have been carried out to evaluate the effect of those conditions at morphological levels as well as to analyze different metabolites, aiming to detect early stress markers involved in the acquisition of tolerance. To enable a broader understanding of these mechanisms, two Pinus species from contrasting habitats have been employed in all experiments: $P$. radiata and $P$. halepensis.

\section{Stress Modulation on Initial Stage of Somatic Embryogenesis}

\section{The Outcome of Different Water Availabilities and Temperatures at Initial Stages}

As referred above, two Pinus species have been used in our experiments: $P$. radiata and $P$. halepensis. Radiata pine is a conifer native from California and México. It has a great economic relevance being suitable for a great range of uses due to its rapid and versatile growth and the desirable quality of its pulp and timber. It is the most widely planted pine in the world (Espinel et al. 1995; Dungey et al. 2009). $P$. halepensis Mill., commonly named Aleppo pine, is a species native to the Mediterranean region, widespread from Spain to Algeria (Botella et al. 2010). It is important for environmental conservation (Montalbán et al. 2013), due to its great ecological plasticity, since it can thrive under semi-arid climatic conditions in a wide variety of soils and can be used in large afforestations (Maestre and Cortina 2004).

With prior protocols established for SE in both species, two separate experiments per species that investigated the stress influence along the process by applying different environmental conditions, at induction and proliferation steps, were performed as indicated in Fig. 7.1.

In the initial set of experiments, different gellan gum concentrations $(2,3$, and $\left.4 \mathrm{gL}^{-1}\right)$, to increase or reduce water availability, were added to the induction media, and the explants were then stored at three different temperatures $\left(18,23\right.$, and $\left.28{ }^{\circ} \mathrm{C}\right)$. Immature megagametophytes from four seed families in $P$. radiata (GarcíaMendiguren et al. 2016a) and five in P. halepensis (Pereira et al. 2016) were used as explants. Different environmental conditions were applied only at the induction 


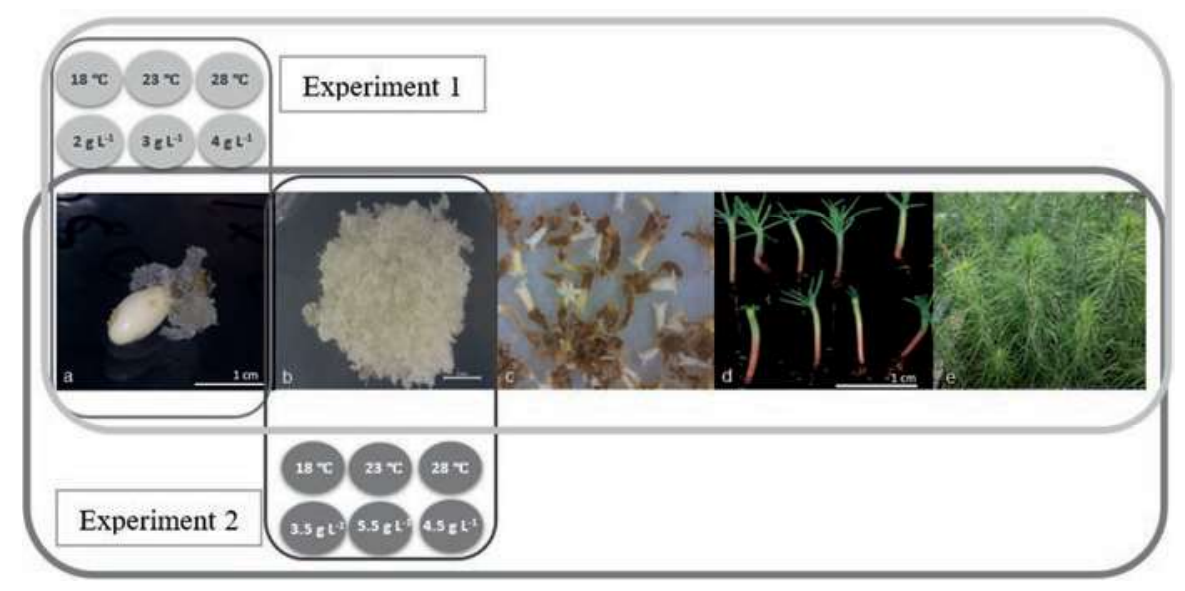

Fig. 7.1 Scheme of the experiments carried out in order to test the stress influence along the process by applying different environmental conditions, at induction and proliferation steps of somatic embryogenesis in Pinus spp. (a) Embryogenic mass extrusion from immature megagametophyte of $P$. halepensis. (b) Established embryogenic mass in proliferation of $P$. halepensis. (c) Somatic embryos obtained from embryogenic masses of $P$. radiata. (d) In vitro germinated somatic plantlets of $P$. halepensis and (e) acclimatized somatic plants of $P$. radiata growing in the greenhouse. Each experiment comprised nine different treatments and was individually developed for each species

stage, and then the cultures were maintained at standard conditions on the subsequent stages of the process. In both species, initiation rates of embryonal masses (EMs) were significantly different among seed families, temperatures, and gellan gum concentrations (García-Mendiguren et al. 2016a; Pereira et al. 2016). As expected, both showed significant differences on initiation rates between seed families. Since the effect of the mother plant cannot be equally reproduced unless the same families are used for a future experiment, a higher number of family seeds can reduce the variability of the results (Montalbán et al. 2013, 2015). Regarding the water availability, it is known that water availability in the culture media plays an important role in the phases of EM initiation and proliferation (Choudhury et al. 2008; García-Mendiguren et al. 2016a), and both species showed higher initiation rates in explants cultured with the lowest water availability $\left(4 \mathrm{gL}^{-1}\right)$. These results agree with reports in P. monticola (Percy et al. 2000) and P. pinea (Carneros et al. 2009) and are in contrast to some authors who have shown that when gellan gum increases, the initiation of embryogenesis is negatively affected (Harry and Thorpe 1991; Becwar et al. 1995; Pullman and Skryabina 2007). Nonetheless, the highest initiation rate of EMs in P. halepensis was obtained in cultures maintained at $23{ }^{\circ} \mathrm{C}$ (control temperature), while the lowest temperature, $18{ }^{\circ} \mathrm{C}$, led to better initiation rates on $P$. radiata. Bonga et al. (2010) suggested that changes in temperature regimes might improve initiation and proliferation since temperature stress may promote cellular reprogramming. We relate this difference to the optimal temperature at which these species grow in the field, which is usually lower in the case of 
radiata pine. Concerning the subsequent phases of SE in Aleppo pine, the initiation temperature only had a significant effect at proliferation stage, with initiation temperature $18{ }^{\circ} \mathrm{C}$ leading to lower rates. All embryogenic cell lines (ECLs) were able to produce somatic embryos ( $s e$ ), and there were no differences on the number of se produced or at the germination rates. García-Mendiguren et al. (2016a) showed that EMs of radiata initiated at $28{ }^{\circ} \mathrm{C}$ exhibited higher proliferation percentages and produced the highest number of $s e$. A second experiment was developed with the same purpose, to evaluate the effect of different environmental conditions along the SE process, for both species at the proliferation stage. In this case, different gellan gum concentrations $\left(3.5,4.5\right.$, and $\left.5.5 \mathrm{gL}^{-1}\right)$ were added to the proliferation media, and again, the explants were stored at three different temperatures $(18,23$, and $\left.28{ }^{\circ} \mathrm{C}\right)$. Standard conditions were applied at all other stages of the process.

The results presented by García-Mendiguren et al. (2016a) on radiata pine showed that more water availability, $3.5 \mathrm{gL}^{-1}$ gellan gum, led to lower proliferation rates. EMs incubated at the highest temperature, $28^{\circ} \mathrm{C}$, also showed lower proliferation rates. Nonetheless, no significant effects on maturation rates or the number of SE produced were observed. Pereira et al. (2017) gave results for Aleppo pine, reporting opposite findings in $P$. radiata, showed that the interaction between temperature and water availability significantly affected the number of se produced per gram, and germinations rates, in agreement with results obtained by Kvaalen and Johnsen (2008) in Picea abies. A significantly higher number of se were obtained when the cultures were proliferated at $28{ }^{\circ} \mathrm{C}$ with $3.5 \mathrm{gL}^{-1}$ gellan gum, whereas the highest germination rate was achieved from EMs proliferated at $28{ }^{\circ} \mathrm{C}$ in a culture media supplemented with $5.5 \mathrm{gL}^{-1}$ gellan gum. As a conclusion, it can be stated that regarding $P$. radiata the initiation stage is crucial to all further steps, from initiation to maturation of se, having long-term effects on embryogenesis. On the other hand, with $P$. halepensis, manipulation of environmental conditions during the initiation stage only influenced the success of initiation and proliferation, while during the proliferation of embryonal masses, it caused an effect only several months later, in the production of somatic plants at the germination stage.

\section{Protein Profiles of Somatic Embryos Derived from Different Water Availabilities and Temperatures at Initials Stages}

SE can occur in tissue and cell cultures of a wide range of species, from herbaceous to woody plants. Nonetheless, the mechanisms of initiation and se development are not fully understood, so in recent years SE has been studied using discovery proteomics, in order to get deeper insight into the process (Klubicová et al. 2017). Proteomics is a very useful tool for studying stress tolerance, allowing the identification and quantification of stress-tolerance-associated proteins (Pinheiro et al. 2014), with the possibility to use protein markers for improving selection. The utilization of the global transcript expression or protein profiling (Lippert et al. 2005; 
Zhao et al. 2015) has been used as an approach to generate such markers and for a better understanding of SE regulation. In this sense, a $2 \mathrm{D}$ proteomic analysis was carried out, aiming to determine if the abovementioned environmental conditions during the induction phase of SE in $P$. radiata resulted in differences in the protein profiles of se (García-Mendiguren et al. 2016b). Protein patterns in se from ECLs from treatments producing high percentages of initiation $\left(18 / 23^{\circ} \mathrm{C}, 4 \mathrm{gL}^{-1}\right)$ and low percentages of initiation $\left(28^{\circ} \mathrm{C}, 2 / 3 \mathrm{gL}^{-1}\right)$ were evaluated and compared. In se from treatments that led to low percentages of initiation, a prominent group of proteins involved in defense responses, such as the osmotically inducible protein OsmC, chaperone protein, and vicilins, was identified. Chaperones are known as heat shock proteins (HSPs), whose biological role is to assist folding of unfolded or misfolded proteins under stress conditions (Efeoğlu 2009), and are also known for their roles in the maturation, as they act as oxidative stress regulators (Marsoni et al. 2008). Proteins associated with other functional groups, such as the response to ROS, important signaling molecules reported to act in plant responses to biotic and abiotic stresses (Delledone et al. 2001), and in the development of SE of conifers (Zhang et al. 2010), or proteins related to gene expression, were also found in lower proportions. The presence of proteins involved in stress and metabolic responses indicates that changing environmental conditions seem to influence all the SE process.

\section{Effect of Extreme Temperature Stress on the Induction Phase}

Following on from the studies on the effects of different gelling agents and culture temperatures in the success of the SE process, further experiments were carried out in radiata pine with extreme temperature stress, in order to examine if those stresses can establish an epigenetic mark in the embryogenic cells, leading to plants with different ability to grow ex vitro under unfavorable conditions. For these studies, high temperatures $\left(30,40,50\right.$, and $\left.60{ }^{\circ} \mathrm{C}\right)$ for different incubation periods during initiation (Castander-Olarieta et al. 2019) were applied. Simultaneously, the success of the SE process was evaluated, and different morphological and molecular analyses were performed.

In line with previous studies (García-Mendiguren et al. 2016a; Pereira et al. 2016), the application of high temperatures for long exposure time periods during initiation had detrimental effects during the first steps of the SE process (initiation and proliferation), which reduced considerably the genetic diversity that could be induced by this technique. Nonetheless, the same treatments provoked an increase in the production of $s e$, which agrees with the results reported by Fehér (2015). These authors postulated that stress acts like a selective pressure during initial phases of SE, improving the efficiency of the forthcoming steps. It is worth highlighting that the se obtained presented morphologies that usually led to low germination and rooting rates (Pullman et al. 2003). On the other hand, our results suggest that high temperatures for short periods did not provoke a decrease in initiation or 
proliferation rates, but also promoted the production of se. Moreover, in this case, the embryos obtained were of better quality, bigger, and more elongated, suggesting that mild stresses enhance not only the production but also the quality of the embryos formed. For a better understanding of the effects of thermal stress during SE, an exhaustive micromorphological and ultrastructural analysis of the EMs was carried out. This study confirmed the presence of three cell types (embryogenic cells, tubelike cells, and suspensor cells) and three organizational structures (PEMI, PEMII, and PEMIII) in EMs, as already observed for other conifer species by Filonova et al. (2000) and Steiner et al. (2016). As a general trend, the application of high temperatures resulted in the loss of polarity and cellular disorganization of embryogenic structures (Fig. 7.2a, b, c, d), coupled with an increase in the number of vacuoles, plastolysome-like structures, whorls by cytoplasmic membranes, and starch grains around the nuclei (Fig. 7.3), all of them symptoms of programmed cell death (Smertenko and Bozhkov 2014).
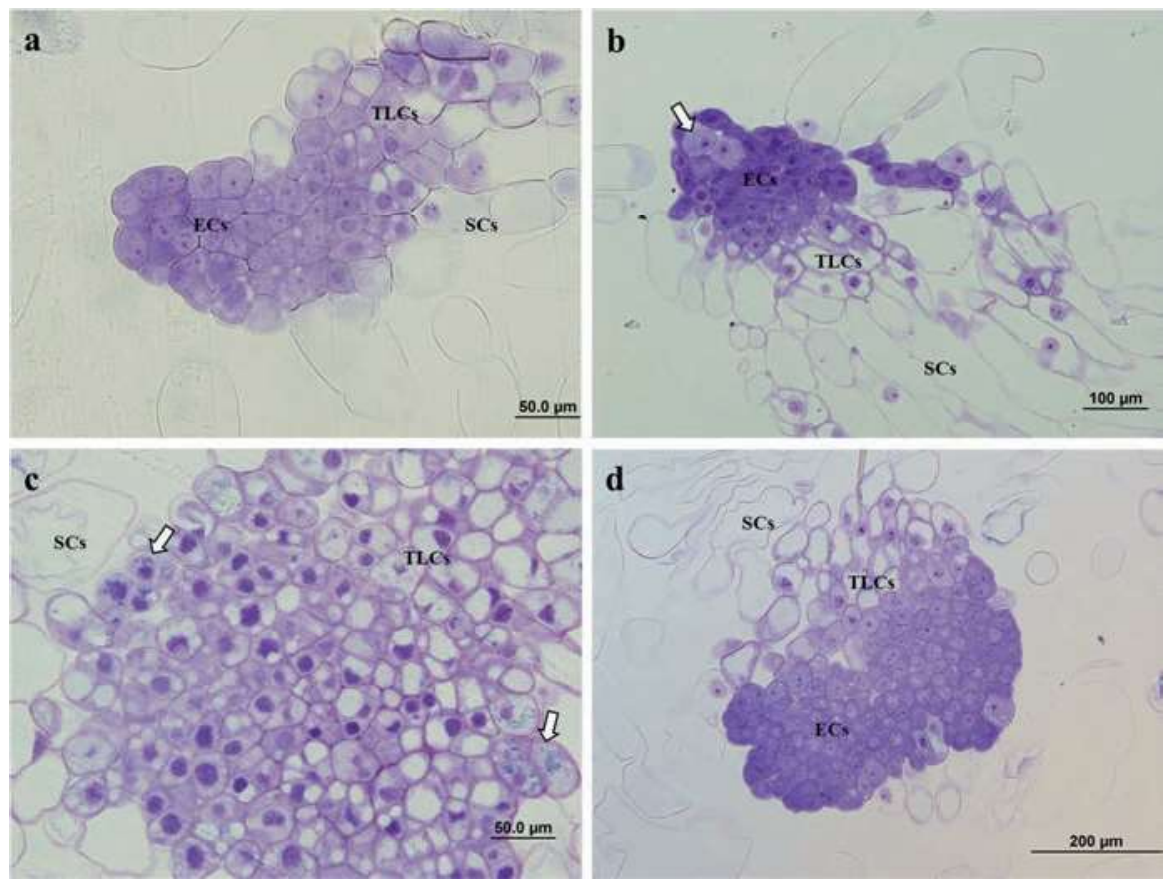

Fig. 7.2 Light microscopy and histochemical analyses of proembryogenic masses of Pinus radiata induced at different temperatures. The pictures show different cell types: embryogenic cells (ECs), tube-like cells (TLCs), and suspensor cells (SCs). (a) PEMIII from $23^{\circ} \mathrm{C}$ presenting a clear polarization and well-organized structure. (b) PEMIII from $40^{\circ} \mathrm{C}$ starting to lose polarization with enlarged TLCs arising in the middle of embryonal areas (arrow). (c) Embryonal area from $50{ }^{\circ} \mathrm{C}$ showing cells with advanced symptoms of programmed cell death (high vacuolation, compacted heterochromatin) and lost polarization. Small phenolic grains are also visible (arrows). (d) PEMIII from $60{ }^{\circ} \mathrm{C}$ forming a big cluster of compacted and well-organized ECs 

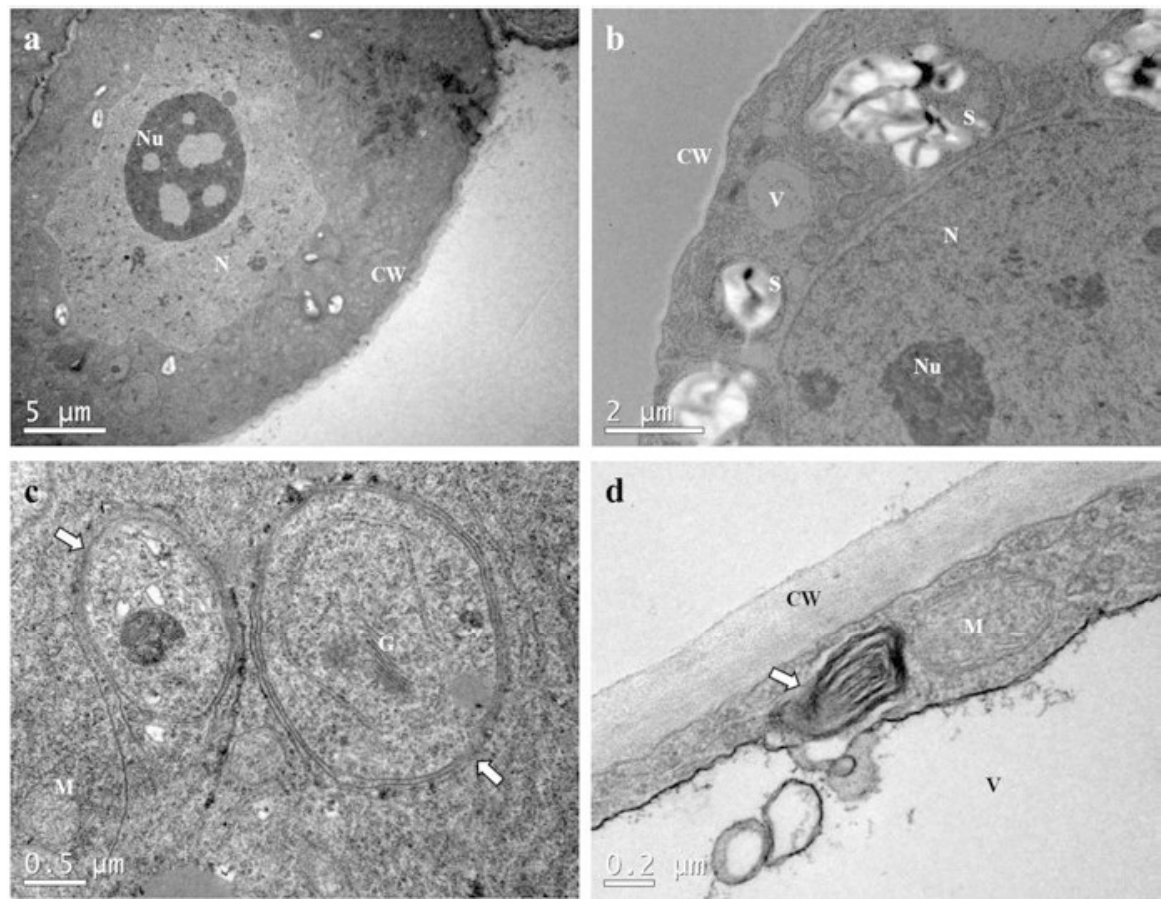

Fig. 7.3 Transmission electron microscopy images of ECs and TLCs from proembryogenic masses initiated at different temperatures. Cells present a great variety of organelles: nuclei $(\mathrm{N})$, nucleoli $(\mathrm{Nu})$, cell wall $(\mathrm{CW})$, vacuole $(\mathrm{V})$, mitochondria $(\mathrm{M})$, Golgi bodies $(\mathrm{G})$, and plastids with starch grains (S). (a) ECs from $23{ }^{\circ} \mathrm{C}$ with a dense cytoplasm and just a few S. (b) Details of ECs from $40{ }^{\circ} \mathrm{C}$ showing symptoms of programmed cell death such as a great number of $\mathrm{V}$ and $\mathrm{S}$ surrounding the N. Plastolysome-like structures engulfing different organelles (c) and whorls of cytoplasmatic membranes (d) from ECs and TLCs from $50{ }^{\circ} \mathrm{C}$ treatment, respectively (arrows)

Activation of programmed cell death by temperature was also reported by DaMatta and Cochicho Ramalho (2006). This phenomenon is known to increase the formation of suspensor cells (Abrahamsson et al. 2012), which together with the accumulation of starch grains around the nuclei are the principal causes of loss of embryogenic competence and formation of abnormal se (Morel et al. 2014; Merino et al. 2018). This was also observed with the application of high temperatures for long exposure times in P. radiata (Castander-Olarieta et al. 2019).

It is noticeable nevertheless that the same studies revealed an enhancement in the embryo formation when pulse-like treatments were applied. These conditions favored the presence of bigger and more developed embryogenic areas (Fig. 7.2d), which may explain the increase in embryo production and embryo quality previously observed.

Among the multiple fine-tuning strategies developed by plants against stress, readjustment of biochemical pathways and accumulation of elevated amounts of metabolites are two important examples. Heat and drought have overlapping roles 
(Jia et al. 2017) and are known to activate similar molecular mechanisms driven by osmotic imbalances (Shinozaki et al. 2003; Gimeno et al. 2009). In forest species, these events lead to an enhanced synthesis and accumulation of soluble carbohydrates and amino acids (Patakas et al. 2002).

Sugars are described as taking an active part in numerous stress-mediated signal transduction pathways, and their activity as osmolytes, membrane stabilizers, and oxygen radical scavengers is well documented (Moradi et al. 2017; Woodrow et al. 2017). However, Castander-Olarieta et al. (2019) did not find pronounced differences in the carbohydrate profile of EMs exposed to different temperatures. However, the same authors detected significant differences in the amounts of certain amino acids, some of which are well known as playing important roles in plant stress tolerance acquisition. They are involved in osmotic adjustment, $\mathrm{pH}$ regulation, detoxification of reactive oxygen species, and synthesis of secondary metabolites (Corcuera et al. 2012; De Diego et al. 2015).

In opposition to numerous studies that highlight the importance of proline as one of the most active amino acids in stress responses (Wang et al. 2019). CastanderOlarieta et al. (2019) showed a clear participation of branched-chain amino acids in response to high temperatures. Isoleucine was the best example, whose levels increased with higher temperatures, suggesting its contribution to the synthesis of stress-induced proteins and to the regulation of gene expression (Joshi et al. 2010). Tyrosine also accumulated in all heat-shock treatments. This amino acid is a precursor of a wide range of secondary metabolites, among which phenolic compounds are of great importance because of their antioxidant role (Eliášová et al. 2017). Interestingly, light microscopy analysis carried out by the same authors revealed the presence of these compounds in the vacuoles of EMs subjected to the highest temperatures (Fig. 7.2c).

\section{Future Perspectives}

After having tested the feasibility of modulating the productivity and the quality of se by modifying different culture conditions during initial steps of SE in two pine species from contrasting habitats, our research team is also paying special attention to the effect of extreme temperatures $\left(40,50\right.$, and $\left.60{ }^{\circ} \mathrm{C}\right)$ for different incubation periods, during the initiation phase, in SE of $P$. halepensis, for which information in this regard is still scarce. In that way we would be able to obtain more information about the different behaviors of this pine species and the mechanisms they employ to face stress.

Likewise, we consider it is of great interest to unravel the role that phytohormones are playing in these developmental and stress-response processes. Plant hormones, apart from modulating numerous physiological and developmental responses (Wani et al. 2016) and being essential during in vitro organogenesis and SE (Moncaleán et al. 2003, 2005, 2018; Montalbán et al. 2011), are active compounds during stress responses (De Diego et al. 2012, 2015). 
Following the studies previously described (García-Mendiguren et al. 2016b), a deep study of the proteomic response of EMs and se to extreme temperatures will be performed. Proteomics is a very useful tool for studying stress response. The identification and quantification of proteins associated with stress-tolerance response accompanied with the possibility to use protein markers for improving selection can help the understanding of SE regulation, the mechanisms involved in the process, and the possible tolerance of the plants obtained (Klubicová et al. 2017).

Furthermore, we are also testing the drought resilience of somatic plants generated from EMs cultured under high temperatures, in order to assess if all the changes observed in previous studies at in vitro stages persist until reaching plant level and alter their capacity to face stress. This could prove a great advance toward the production of plants pre-adapted to unfavorable conditions. Finally, we are examining the expression patterns of stress-related genes and their methylation state on EMs, $s e$, in vitro somatic plants and plants subjected to stress in the greenhouse.

\section{Funding}

This research was funded by MINECO (Spanish Government) project (AGL2016-76143-C4-3R), BIOALI-CYTED (P117RT0522), DECO (Basque government, Ayudas de formación a jóvenes investigadores y tecnólogos), Renature: Projecto ReNature (Centro-01-0145-FEDER-000007) - Valorização dos Recursos Naturais Endógenos da Região Centro, and Portuguese Foundation for Science and Technology (FCT), POCH (Programa Operacional Capital Humano) (SFRH/ BD/123702/2016) and MULTIFOREVER (Project MULTIFOREVER is supported under the umbrella of ERA-NET cofund Forest Value by ANR (FR), FNR (DE), MINCyT (AR), MINECO-AEI (ES), MMM (FI) and VINNOVA (SE). Forest value has received funding from the European Union's Horizon 2020 research and innovation programme under agreement $\mathrm{N}^{\mathrm{o}} 773324$.

\section{References}

Abrahamsson, M., Valladares, S., Larsson, E., Clapham, D., \& von Arnold, S. (2012). Patterning during somatic embryogenesis in Scots pine in relation to polar auxin transport and programmed cell death. Plant Cell, Tissue and Organ Culture, 109, 391-400.

Allen, C. D., Macalady, A. K., Chenchouni, H., Bachelet, D., McDowell, N., Vennetier, M., et al. (2010). A global overview of drought and heat-induced tree mortality reveals emerging climate change risks for forests. Forest Ecology and Management, 259, 660-684.

Becwar, M., Chesick, E., Handley, L. III, \& Rutter, M. (1995). Method for regeneration of coniferous plants by somatic embryogenesis. US Patent 5,413,930.

Bonga, J. M., Klimaszewska, K., \& Von Aderkas, P. (2010). Recalcitrance in clonal propagation, in particular of conifers. Plant Cell, Tissue and Organ Culture, 100, 241-254.

Botella, L., Santamaría, O., \& Diez, J. J. (2010). Fungi associated with the decline of Pinus halepensis in Spain. Fungal Diversity, 40, 1-11. 
Carneros, E., Celestino, C., Klimaszewska, K., Park, Y. S., Toribio, M., \& Bonga, J. M. (2009). Plant regeneration in Stone pine (Pinus pinea L.) by somatic embryogenesis. Plant Cell, Tissue and Organ Culture, 98, 165-178.

Castander-Olarieta, A., Montalbán, I. A., De Medeiros Oliveira, E., Dell'Aversana, E., D’Amelia, L., Carillo, P., et al. (2019). Effect of thermal stress on tissue ultrastructure and metabolite profiles during initiation of radiata pine somatic embryogenesis. Frontiers in Plant Science, 9, 1-16.

Choudhury, H., Kumaria, S., \& Tandon, P. (2008). Induction and maturation of somatic embryos from intact megagametophyte explants in Khasi pine (Pinus kesiya Royle ex. Gord.). Current Science, 95, 1433-1438.

Conrath, U., Beckers, G. J. M., Langenbach, C. J. G., \& Jaskiewicz, M. R. (2015). Priming for enhanced defense. Annual Review of Phytopathology, 53, 97-119.

Corcuera, L., Gil-Pelegrin, E., \& Notivol, E. (2012). Aridity promotes differences in proline and phytohormone levels in Pinus pinaster populations from contrasting environments. Trees: Structure and Function, 26, 799-808.

DaMatta, F. M., \& Cochicho Ramalho, J. D. (2006). Impacts of drought and temperature stress on coffee physiology and production: A review. Brazilian Journal of Plant Physiology, 18, 55-81.

Davies, W. J., Zhang, J., Yang, J., \& Dodd, I. C. (2011). Novel crop science to improve yield and resource use efficiency in water-limited agriculture. The Journal of Agricultural Science, 149, $123-131$.

De Diego, N., Pérez-Alfocea, F., Cantero, E., Lacuesta, M., \& Moncaleán, P. (2012). Physiological response to drought in radiata pine: Phytohormone implication at leaf level. Tree Physiology, 32, 435-449.

De Diego, N., Saiz-Fernández, I., Rodríguez, J. L., Pérez-Alfocea, P., Sampedro, M. C., Barrio, R. J., et al. (2015). Metabolites and hormones are involved in the intraspecific variability of drought hardening in radiata pine. Journal of Plant Physiology, 188, 64-71.

Delledone, M., Zeier, J., Marocco, A., \& Lamb, C. (2001). Signal interactions between nitric oxide and reactive oxygen intermediates in the plant hypersensitive disease resistance response. Proceedings of the National Academy of Sciences of the United States of America, 98, $13454-13459$.

Duliè, V., Zhang, Y., \& Salathé, E. P. (2013). Changes in twentieth-century extreme temperature and precipitation over the western United States based on observations and regional climate model simulations. Journal of Climate, 26, 8556-8575.

Dungey, H. S., Brawner, J. T., Burger, F., Carson, M., Henson, M., Jefferson, P., et al. (2009). A new breeding strategy for Pinus radiata in New Zealand and New South Wales. Silvae Genetica, 58, 28-38.

Efeoğlu, B. (2009). Heat shock proteins and heat shock response in plants. Gazi University Journal of Science, 22, 67-75.

Eliášová, K., Vondráková, Z., Malbeck, J., Trávníčková, A., Pešek, B., Vágner, M., et al. (2017). Histological and biochemical response of Norway spruce somatic embryos to UV-B irradiation. Trees: Structure and Function, 31, 1279-1293.

Espinel, S., Aragonés, A., \& Ritter, E. (1995). Performance of different provenances and of the local population of the Monterrey pine (Pinus radiata D Don) in northern Spain. Annals of Forest Science, 52, 515-519.

Fehérm, A. (2015). Somatic embryogenesis - stress-induced remodeling of plant cell fate. Biochimica et Biophysica Acta, Gene Regulatory Mechanisms, 1849, 385-402.

Feller, U., \& Vaseva, I. I. (2014). Extreme climatic events: Impacts of drought and high temperature on physiological processes in agronomically important plants. Frontiers in Environmental Science, 2, 1-17.

Fenning, T. M., Walter, C., \& Gartland, K. (2008). Forest biotech and climate change. Nature Biotechnology, 26, 615-617.

Filonova, L. H., Bozhkov, P. V., Brukhin, V. B., Daniel, G., Zhivotovsky, B., \& von Arnold, S. (2000). Two waves of programmed cell death occur during formation and development of somatic embryos in the gymnosperm, Norway spruce. Journal of Cell Science, 113, 4399-4411. 
García-Mendiguren, O., Montalbán, I. A., Goicoa, T., Ugarte, M. D., \& Moncaleán, P. (2016a). Environmental conditions at the initial stages of Pinus radiata somatic embryogenesis affect the production of somatic embryos. Trees: Structure and Function, 30, 949-958.

García-Mendiguren, O., Montalbán, I. A., Correia, S., Canhoto, J., \& Moncaleán, P. (2016b) Different environmental conditions at initiation of radiata pine somatic embryogenesis determine the protein profile of somatic embryos. Plant Biotechnology, 33, 143-152.

Gimeno, T. E., Pas, B., Lemos-Filho, J. P., \& Valladares, F. (2009). Plasticity and stress tolerance override local adaptation in the responses of Mediterranean holm oak seedlings to drought and cold. Tree Physiology, 29, 87-98.

Harry, I. S., \& Thorpe, T. A. (1991). Somatic embryogenesis and plant regeneration from mature zygotic embryos of red spruce. Botanical Gazette, 152, 446-452.

Heringer, A. S., Santa-Catarina, C., \& Silveira, V. (2018). Insights from proteomic studies into plant somatic embryogenesis. Proteomics, 18, 1700265.

Jia, J., Zhou, J., Shi, W., Cao, X., Luo, J., Polle, A., et al. (2017). Comparative transcriptomic analysis reveals the roles of overlapping heat-/drought-responsive genes in poplars exposed to high temperature and drought. Scientific Reports, 7, 43215.

Joshi, V., Joung, J.-G., Fei, Z., \& Jander, G. (2010). Interdependence of threonine, methionine and isoleucine metabolism in plants: Accumulation and transcriptional regulation under abiotic stress. Amino Acids, 39, 933-947.

Klubicová, K., Uvácková, L., Danchenko, M., Nemecek, P., Skultéty, L., Salaj, J., \& Salaj, T. (2017). Insights into the early stage of Pinus nigra Arn. somatic embryogenesis using discovery proteomics. Journal of Proteomics, 3, 99-111.

Kvaalen, H., \& Johnsen, Ø. (2008). Timing of bud set in Picea abies is regulated by a memory of temperature during zygotic and somatic embryogenesis. The New Phytologist, 177, 49-59.

Larkindale, J., \& Knight, M. R. (2002). Protection against heat stress-induced oxidative damage in Arabidopsis involves calcium, abscisic acid, ethylene, and salicylic acid. Plant Physiology, $128,682-695$.

Lippert, D., Zhuang, J., Ralph, S., Ellis, D. E., Gilbert, M., Olafson, R., Ritland, K., Ellis, B., Douglas, C. J., \& Bohlmann, J. (2005). Proteome analysis of early somatic embryogenesis in Picea glauca. Proteomics, 5, 461-473.

Maestre, F. T., \& Cortina, J. (2004). Are Pinus halepensis plantations useful as a restoration tool in semiarid Mediterranean areas? Forest Ecology and Management, 198, 303-317.

Manzanera, J. A., Gómez-Garay, A., Pintos, B., Rodríguez-Rastrero, M., Moreda, E., Zazo, J., et al. (2017). Sap flow, leaf-level gas exchange and spectral responses to drought in Pinus sylvestris, Pinus pinea and Pinus halepensis. iForest, 10, 204-214.

Marsoni, M., Bracale, M., Espen, L., Prinsi, B., Negri, S., \& Vannini, C. (2008). Proteomic analysis of somatic embryogenesis in Vitis vinifera. Plant Cell Reports, 27, 347-356.

Merino, I., Abrahamsson, M., Larsson, E., \& von Arnold, S. (2018). Identification of molecular processes that differ among Scots pine somatic embryogenic cell lines leading to the development of normal or abnormal cotyledonary embryos. Tree Genetics \& Genomes, 14, 34. https:// doi.org/10.1007/s11295-018-1247-z.

Moncaleán, P., Cañal, M. J., Fernández, H., Fernández, B., \& Rodríguez, A. (2003). Nutritional and gibberellic acid requirements in kiwifruit vitroponic cultures. In Vitro Cellular \& Developmental Biology. Plant, 39, 49-55.

Moncaleán, P., Alonso, P., Centeno, M. L., Cortizo, M., Rodríguez, A., Fernández, B., et al. (2005) Organogenic responses of Pinus pinea cotyledons to hormonal treatments: BA metabolism and cytokinin content. Tree Physiology, 25, 1-9.

Moncaleán, P., García-Mendiguren, O., Novák, O., Strnad, M., Goicoa, T., Ugarte, M. D., et al (2018). Temperature and water availability during maturation affect the cytokinins and auxins profile of radiata pine somatic embryos. Frontiers in Plant Science, 9, 1898. https://doi. org/10.3389/fpls.2018.01898. 
Montalbán, I. A., De Diego, N., \& Moncaleán, P. (2011). Testing novel cytokinins for improved in vitro adventitious shoots formation and subsequent ex vitro performance in Pinus radiata. Forestry, 84, 363-373.

Montalbán, I. A., Setién-Olarra, A., Hargreaves, C. L., \& Moncaleán, P. (2013). Somatic embryogenesis in Pinus halepensis Mill.: An important ecological species from the Mediterranean forest. Trees: Structure and Function, 27, 1339-1351.

Montalbán, I. A., García-Mendiguren, O., Goicoa, T., Ugarte, M. D., \& Moncaleán, P. (2015) Cold storage of initial plant material affects positively somatic embryogenesis in Pinus radiata. New Forest, 46, 157-165.

Moradi, P., Ford-Lloyd, B., \& Pritchard, J. (2017). Metabolomic approach reveals the biochemical mechanisms underlying drought stress tolerance in thyme. Analytical Biochemistry, 527, 49-62.

Morel, A., Teyssier, C., Trontin, J.-F., Eliášová, K., Pešek, B., Beaufour, M., et al. (2014). Early molecular events involved in Pinus pinaster Ait. somatic embryo development under reduced water availability: Transcriptomic and proteomic analyses. Physiologia Plantarum, 152, 184-201.

Patakas, A., Nikolaou, N., Zioziou, E., Radoglou, K., \& Noitsakis, B. (2002). The role of organic solute and ion accumulation in osmotic adjustment in drought-stressed grapevines. Plant Science, 163, 361-367.

Percy, R. E., Klimaszewska, K., \& Cyr, D. R. (2000). Evaluation of somatic embryogenesis for clonal propagation of western white pine. Canadian Journal of Forest Research, 30, 1867-1876.

Pereira, C., Montalbán, I. A., García-Mendiguren, O., Goicoa, T., Ugarte, M. D., Correia, S., et al. (2016). Pinus halepensis somatic embryogenesis is affected by the physical and chemical conditions at the initial stages of the process. Journal of Forest Research, 21, 143-150.

Pereira, C., Montalbán, I. A., Goicoa, T., Ugarte, M. D., Correia, S., Canhoto, J. M., et al. (2017). The effect of changing temperature and agar concentration at proliferation stage in the final success of Aleppo pine somatic embryogenesis. Forest Systems, 26, 1-4.

Pinheiro, C., Guerra-Guimarães, L., David, T. S., \& Vieira, A. (2014). Proteomics: State of the art to study Mediterranean woody species under stress. Environmental and Experimental Botany, $103,117-127$.

Pullman, G. S., \& Skryabina, A. (2007). Liquid medium and liquid overlays improve embryogenic tissue initiation in conifers. Plant Cell Reports, 26(7), 873-887. https://doi.org/10.1007/ s00299-006-0296-1.

Pullman, G. S., Johnson, S., Peter, G., Cairney, J., \& Xu, N. (2003). Improving loblolly pine somatic embryo maturation: Comparison of somatic and zygotic embryo morphology, germination, and gene expression. Plant Cell Reports, 21(8), 747-758. https://doi.org/10.1007/ s00299-003-0586-9.

Sangwan, V., Örvar, B. L., Beyerly, J., Hirt, H., \& Dhindsa Rajinder, S. (2002). Opposite changes in membrane fluidity mimic cold and heat stress activation of distinct plant MAP kinase pathways. The Plant Journal, 31, 629-638.

Shinozaki, K., Yamaguchi-Shinozaki, K., \& Seki, M. (2003). Regulatory network of gene expression in the drought and cold stress responses. Current Opinion in Plant Biology, 6, 410-417.

Smertenko, A., \& Bozhkov, P. V. (2014). Somatic embryogenesis: Life and death processes during apical-basal pattering. Journal of Experimental Botany, 65, 1343-1360.

Steiner, N., Farias-Soares, F. L., Schmidt, É. C., Pereira, M. L. T., Scheid, B., Rogge-Renner, G. D., et al. (2016). Toward establishing a morphological and ultrastructural characterization of proembryogenic masses and early somatic embryos of Araucaria angustifolia (Bert.) $\mathrm{O}$ Kuntze. Protoplasma, 253, 487-501.

Vacca, R. A., Pinto, M. C. D., Valenti, D., Passarella, S., Marra, E., \& Gara, L. D. (2004). Production of reactive oxygen species, alteration of cytosolic ascorbate peroxidase, and impairment of mitochondrial metabolism are early events in heat shock-induced programmed cell death in Tobacco Bright-Yellow 2 Cells. Plant Physiology, 134, 1100-1112. 
von Arnold, S., Claphama, D., \& Abrahamsson, M. (2018). Embryology in conifers. In F. M. Cánovas (Ed.), Molecular physiology and biotechnology of trees (Advances in botanical research) (pp. 157-184). London: Academic Press.

Wang, X., Mao, Z., Zhang, J., Hemat, M., Huang, M., Cai, J., et al. (2019). Osmolyte accumulation plays important roles in the drought priming induced tolerance to post-anthesis drought stress in winter wheat (Triticum aestivum L.). Environmental and Experimental Botany, 166, 103804.

Wani, S. H., Kumar, V., Shriram, V., \& Sah, S. K. (2016). Phytohormones and their metabolic engineering for abiotic stress tolerance in crop plants. Crop Journal, 4, 162-176.

Woodrow, P., Ciarmiello, L. F., Annunziata, M. G., Pacifico, S., Iannuzzi, F., Mirto, A., et al. (2017). Durum wheat seedling responses to simultaneous high light and salinity involve a fine reconfiguration of amino acids and carbohydrate metabolism. Physiologia Plantarum, 159, 290-312.

Xia, X., Zhou, Y., Shi, K., Zhou, J, Foyer, C. H., \& Yu, J. (2015). Interplay between reactive oxygen species and hormones in the control of plant development and stress tolerance. Journal of Experimental Botany, 66, 2839-2856.

Zhang, S. G., Han, S. Y., Yang, W. H., Wei, H. L., Zhang, M., \& Qi, L. W. (2010). Changes in $\mathrm{H}_{2} \mathrm{O}_{2}$ content and antioxidant enzyme gene expression during the somatic embryogenesis of Larix leptolepis. Plant Cell, Tissue and Organ Culture, 100, 21-29.

Zhao, J., Wang, B., Wang, X., Zhang, Y., Dong, M., \& Zhang, J. (2015). iTRAQ-based comparative proteomic analysis of embryogenic and non-embryogenic tissues of Prince Rupprecht's larch (Larix principis-rupprechtii Mayr). Plant Cell, Tissue and Organ Culture, 120, 655-669. 